the environment in which he now lives. But, although man is good at designing machines, he is not so good at understanding human behaviour, and the introduction of electronic machines could have lamentable social consequences if the personal problems involved are neglected. Many people are bound to be affected personally. Considerable changes of technique cannot be brought about overnight. The period of adjustment is long enough to give those in authority the opportunity of using the means at their disposal, such as retraining schemes and the adaptation of recruitment and wastage-rates, to anticipate consequences and work out the necessary human measures to meet new circumstances. Good personnel management must accompany a developing technology.

T. H. HawkINS

\title{
EPIDEMIOLOGY OF BLACK RUST OF WHEAT
}

A SYMPOSIUM on "Epidemics of Black (Stem) Rust of Wheat" was held in the afternoon of October 7 under the auspices of the British Mycological Society. Mr. L. Ogilvie (National Agricultural Advisory Servico, Bristol) said that the alternate host of black rust, wild barberry, does not appear to be implicated in the origin of uniformly distributed and almost simultaneous epidemics in the southwest of England. It was therefore decided to find whether uredospores are transported from the Continent in the same way as they are carried northwards from Texas into the American wheat belt.

Collaborative investigations which have been proceeding in Western Europe and North Africa since 1958 show that the disease overwinters in the uredospore stage on wheat and grasses in North Africa and Southern Iberia, and spreads northwards in summer. Observations on field crops and on some thirty widely scattered 'rust nurseries' (small plots of varieties of spring wheats) were organized from Bristol. About a fortnight after uredospores were trapped in quantity, rust was found in the fields and from then on became common in most of the southern coastal areas, the Channel Islands and Isles of Scilly and, later, to a lesser degree, in the whole of the southern half of England.

Dr. I. G. Thorpe (National Agricultural Advisory Service, Bristol) stated that the oat, barley, and some grass varieties of Puccinia graminis are not uncommon on barberries in England, but the wheat variety has not been found in recent years. The simultaneous appearance of the disease over a large area suggests a widespread inoculum. Uredospore deposits on spore traps can usually be correlated with air trajectories from countries to the south, as is explained later. Up to the present, the spectrum of rust races recognized in England greatly resembles that of the Iberian Peninsula and France. Mr. H. A. Hyde and Mrs. K. F. Adams (National Museum of Wales, Cardiff) reported that black rust uredospores have been found from May onwards in the spore catches organized by the Asthma and Allergy Research Unit at Cardiff and the Bishop Rock Lighthouse, often before wheat is affected in England. Simultaneous catches of black rust spores have often been made at points more than 150 miles apart. The theory of spore clouds originating from the Continent is supported also by catches in spring of pine pollen, which apparently came from southern Europe.

Mr. W. H. Hogg (Meteorological Office, Bristol) described how air trajectories could be prepared from weather maps, and gave estimates of the errors involved. Uredospore catches in London during the period July 4-10, 1959, were accompanied by air trajectories from the Continent. When the air came from other quarters, spores were few or lacking. Dr. J. M. Hirst (Rothamsted) dealt with theories underlying the liberation, transport and deposition of rust uredospores. Sampling from aircraft traversing southerly airstreams over the English Channel have shown large numbers of spores at heights up to $7,000 \mathrm{ft}$.

Conclusions which may be drawn from the symposium are that a severe black rust epidemic in England depends on susceptible varieties of wheat (all varieties grown here are susceptible to the common West European races of black rust), lateness of the wheat crops, transport of spore clouds arising from epidemics to the south by one or more favourable wind trajectories in late June or early July, and warm and humid weather at the time of infection and for several weeks later.

\section{TROPICAL ECOLOGY}

$\mathrm{E}^{\mathrm{c}}$ COLOGICAL terminology and concepts applicable to, and developed under, temperate conditions sometimes have little relevance to the vegetation of the tropics, and a journal devoted especially to tropical ecology will be welcomed by many as meeting a real need, so long as it does not encourage ecologists in differing climatic zones to overlook the essential unity of their subject.

Nos. 1 and 2 of Vol. 1 of the Bulletin of the Inter national Society for Tropical Ecology give little indication of the extent to which this new journal will, in fact, meet the need which undoubtedly exists. No. 1 contains a presidential address : "Why Tropical Ecology ?" by J. C. Sen Gupta, as well as abstracts of 22 papers, mainly on tropical forests, given at a symposium on forest ecology held at Bombay. In No. 2 are rather longer accounts of 21 papers read at a forest ecosystem symposium which was a part of the ninth International Botanical Congress held at Montreal. There is thus an absence of research papers of the conventional type ; but it is useful to have the views of experts from many countries on forest classification assembled together in a single volume in this way.

No indication is given as to whether succeeding numbers of this journal will be restricted to abstracts of papers read at symposia and conferences, or whether the journal is to restrict itself to tropical 
plant ecology. Until it is possible to see what permanent form this new journal takes, it can be given only a qualified welcome, although a forum in which ecologists of the tropics can discuss their special problems and report on their work is undoubtedly needed.
The Bulletin is edited by Dr. G. S. Puri, general secretary of the Society, 10 Chatham Lines, Allahabad, India, assisted by an editorial board with representatives from Japan, India and Great Britain. It is not priced, but is distributed to members of the Society (annual subscription 15 rupees, or $£ 12 s .6 d$.).

\title{
OBSERVATIONS OF FALL-OUT IN INDIA DURING THE PERIOD OF CESSATION OF NUCLEAR TESTS
}

\author{
By K. G. VOHRA and V. S. BHATNAGAR \\ Atomic Energy Establishment, Trombay, Bombay
}

T

WE recent measurements of fall-out in different parts of the world have provided evidence of a shorter time of residence of fission products in the stratosphere than had been estimated earlier ${ }^{1-5}$. Martell ${ }^{1,2}$ has suggested residence-time in the stratosphere of 6 months-1 year for the tests carried out in the polar regions and 3-5 years for the tests carried out in the equatorial regions. The investigations on fall-out carried out in Norway ${ }^{3}$ have shown that the airborne activity at the ground-level starts increasing shortly after high-yield tests, reaches a peak value in about six to seven months and then decreases with a half-life of about one month. These measurements also suggest a short value of mean residence-time in the stratosphere.

The ground-level airborne fall-out activity in India ${ }^{6}$ after October 1958 showed a trend somewhat similar to that observed in Norway. A rise in airborne activity was observed soon after the completion of high-yield tests carried out in the polar regions in October 1958. This increase continued, and a maximum was reached at all the stations after about four months, that is, during February-March 1959. This activity decreased with a half-life of about 40 days, suggesting residence-time in the atmosphere of about 60 days.

We have also studied the ratio of zirconium-95 and crsium-137 activities in samples of rain-water from Srinagar and Bombay during the period December 1958-September 1959. The change in this ratio with time seems to provide some information regarding the relative proportions of fall-out debris from the old tests and the October 1958 polar tests. The mean residence-time in the atmosphere has also been estimated indirectly from this ratio and is found to be about 60 days.

The obvious consequence of short residence-time in the stratosphere is an increase in the external gamma-radiation dose for several months after high-yield tests. The radiation dose from the gamma-emitting isotopes (zirconium-95 + niobium95), (cerium-144 + praseodymium-144), ruthenium106 and cæsium-137 after the October 1958 test series has been estimated from the observed levels of activity.

\section{Airborne Radioactivity}

Fig. I gives the concentrations of radioactive fallout fission products in the air at ground-level at different stations in India for the period October 1958-June 1959. The airborne radioactivity shows a steady increase after October 1958, reaching a peak value in about four months. The peak in activity is observed at all the stations, except Ootacamund, during the months of February and March, after which the activity decreases with a half-life of about one month.

The increase in activity to the peak value during the period of about four months after the October 1958 test series may be explained as due to the storage of the debris in the troposphere determined by the mean residence-time in the troposphere, which is of the order of $20-30$ days. The decrease in airborne activity at ground-level will be governed by the trend of decrease in the troposphere, which in turn would depend on the residence-time in the stratosphere.

The levels of airborne radioactivity averaged for all the stations for each month and corrected for radioactive decay to October 15,1958 , have also been plotted in Fig. 1, and a smooth graph has been drawn through these points to give a picture of the general trend of variations of airborne activity at groundlevel. This graph shows that, after the peak is reached, the activity decreases with a half-life of 40 days, as determined from the slope, corresponding to a mean residence-time in the atmosphere of about 60 days.

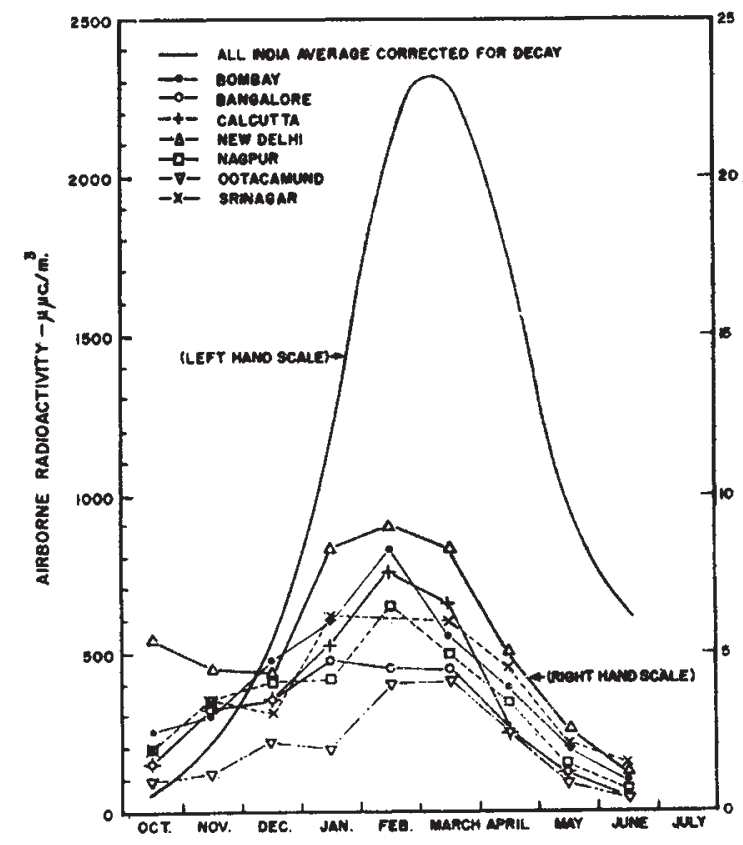

Fig. 1. Average monthly levels of airborne radioactivity at different stations in India during October 1958-June 1959. The smooth curve shows the level of airborne radioactivity averaged for all the stations for each month and corrected for radioactive decay to October 15,1958 